University of Texas Rio Grande Valley

ScholarWorks @ UTRGV

$11-2020$

\title{
Why do people patronize donation-based crowdfunding platforms? An activity perspective of critical success factors
}

\author{
Yali Zhang \\ Chrissie Diane Tan \\ Jun Sun \\ The University of Texas Rio Grande Valley, jun.sun@utrgv.edu \\ Zhaojun Yang
}

Follow this and additional works at: https://scholarworks.utrgv.edu/is_fac

Part of the Business Commons

\section{Recommended Citation}

Zhang, Y., Tan, C. D., Sun, J., \& Yang, Z. (2020). Why do people patronize donation-based crowdfunding platforms? An activity perspective of critical success factors. Computers in Human Behavior, 112, 106470. https://doi.org/10.1016/j.chb.2020.106470

This Article is brought to you for free and open access by the Robert C. Vackar College of Business \& Entrepreneurship at ScholarWorks @ UTRGV. It has been accepted for inclusion in Information Systems Faculty Publications and Presentations by an authorized administrator of ScholarWorks @ UTRGV. For more information, please contact justin.white@utrgv.edu, william.flores01@utrgv.edu. 


\begin{abstract}
As a special type of social information systems, crowdfunding platforms draw researchers' attention in recent years for their increasing popularity. In supplement to big-data analyses on usergenerated content, behavioral research using survey and interview observations provide insights on why people like or hesitate to use such platforms. Nevertheless, extant studies focus on user intention and equity/reward-based projects, leaving the knowledge body on why people actually engage in donation-based crowdfunding underdeveloped. Based on Activity Theory, this study explores the critical success factors of crowdfunding in terms of website acceptance, crowd familiarity, and donation reciprocity. It then develops a research model that adapts relevant constructs from e-commerce and charitable behavior literature to predict user trust and readiness leading to actual donation. To test the hypothesized relationships, a structural equation modeling analysis was performed on 744 survey responses collected from crowdfunding platform users in multiple countries. Results provide supporting evidence to most hypotheses and confirm the importance of factors related to the technological system as well as social collaboration in the crowdfunding activity.
\end{abstract}

Keywords:

donation-based crowdfunding, website acceptance, crowd familiarity, donation reciprocity, user trust, crowdfunding readiness. 
Why Do People Patronize Donation-based Crowdfunding Platforms? An Activity Perspective of

\section{Critical Success Factors}

\section{Introduction}

As the Internet continues to change our lives, donation practices are also being adapted to the evolving technology, making conventional fundraising methods almost obsolete (Hoefer, 2012). For instance, event organizers use online tools to promote publicity and recruit volunteers along with fundraising (Reddick \& Ponomariov, 2012). Experiencing rapid growth in recent years, in particular, crowdfunding has emerged as a new form of micro-financing on the Internet (Massolution, 2015). Popular crowdfunding sites such as Kickstarter and Indiegogo mainly concern with equity-based or reward-based fundraising projects (Cho \& Kim, 2017; Herrero, Hernández-Ortega, \& San Martín, 2020; Vulkan, Åstebro, \& Sierra, 2016). As an online philanthropy innovation, charitable crowdfunding gain popularity with more and more donationbased projects (Cox et al., 2018; D. Lee \& Park, 2020; Y.-Z. Li, He, Song, Yang, \& Zhou, 2018).

Charitable organizations help those in need in addition to government efforts. Compared with traditional fundraising methods, crowdfunding reaches out to a broader range of people for their donation. Despite the rising popularity of such donation-based crowdfunding, most researchers focus on equity-based or reward-based crowdfunding (Herrero et al., 2020; Shneor \& Munim, 2019; Strohmaier, Zeng, \& Hafeez, 2019; Vulkan et al., 2016; Z. Wang \& Yang, 2019). The few existing empirical studies on donation-based crowdfunding predict user intention to donate rather than the actual donation behavior (L. Liu, 2018; T. Wang, Li, Kang, \& Zheng, 2019). The literature on philanthropy behavior suggests a large gap between donation intention and actual donation (Bekkers \& Wiepking, 2011). To obtain an in-depth understanding, this study examines 
the critical success factors of crowdfunding that are conducive to user trust and readiness leading to actual donation.

The success of crowdfunding platforms depends on the interaction and collaboration among users, including donors and donees. For a systematic understanding of user engagement with such social information systems, this study employs the Activity Theory, a sociopsychology Meta theory that examines collective and tool-mediated human behavior. The understanding leads to the development of a research model on how website acceptance, crowd familiarity, and donation reciprocity affect behavioral outcomes. To test the hypothesized relationships, survey observations were collected from multiple countries. The findings provide insights into the best practices of promoting crowdfunding success.

\section{Research Background}

Based on research objectives and data sources, there are three approaches of crowdfunding research: 1) platform-specific research based on user-generated data from a particular crowdfunding platform; 2) secondary-data research based on published reports and statistics; 3) behavioral research based on qualitative interviews or quantitative surveys with the participants of various platforms (Stasik \& Wilczyńska, 2018). The first approach reveals actual platform usage patterns from raw and manually coded crowdfunding project online information (Bi, Liu, \& Usman, 2017; S. Chen, Thomas, \& Kohli, 2016). The patterns identified provide deeper insights than crosssectional summary statistics like active/inactive users, visit frequency, and average donation amount. Nevertheless, the second approach keeps track of the changes in such statistics to assess policy/regulation effectiveness (e.g., tax exemption), and the high-level findings are helpful for the healthy development of the whole crowdfunding industry (Dushnitsky, Guerini, Piva, \& RossiLamastra, 2016; Silver \& Khatri, 2016). Unlike the first two approaches that examine how users 
participate in crowdfunding based on observable behavior, the last one focuses on psychological behavior to address the question of why they want to play active roles or just sit on their hands.

Except for secondary-data research, the other two approaches require researchers to collect primary data: objective observations from a particular platform or subjective observations from crowdfunding users. As crowdfunding is enabled by social computing, platform-specific research is similar to the social media analysis with the big data that users generate on a popular platform like Twitter or Facebook (Ghani, Hamid, Hashem, \& Ahmed, 2019). Researchers use crawling bots to gather objective observations that exist as database records, and run numeric (statistical, social network, and trend) and textual (semantic and content) analyses (I. Lee, 2018). In contrast, behavioral research requires investigators to collect subjective observations from social platform users through interviews and surveys to find out why they act in a certain way from the psychological perspective (Zolkepli \& Kamarulzaman, 2015). Whereas big-data analyses help researchers identify the patterns underlying massive records, subjective responses gathered from sampled users allow them to investigate the relationships among psychological constructs (Neubaum, Rösner, Rosenthal-von der Pütten, \& Krämer, 2014). The two approaches supplement each other as platform-specific research examines "how" people participate in technologymediated interactions but behavioral research addresses "why" they engage in crowdfunding.

So far, not many crowdfunding studies have pursued the behavioral research approach, especially using the survey methodology to collect user responses for the quantitative assessment of hypothesized relationships among behavioral constructs such as motivation, trust, and intention. A search on Google Scholar found five such publications, among which four are on reward-based crowdfunding (Herrero et al., 2020; Shneor \& Munim, 2019; Strohmaier et al., 2019; Z. Wang \& Yang, 2019) and the other one on entrepreneur-oriented crowdfunding (Sahaym, Datta, \& Brooks, 
2019). This study attempts to fill in the research gap by conducting a multi-nation survey of user participation in donation-based crowdfunding. In particular, it investigates the critical success factors of crowdfunding platforms concerning user engagement.

Donation behavior is a research area for understanding donors and strategizing how to convince more into giving. Previous studies on donation behavior generally use demographic and socio-economic factors such as age, gender, income level, and educational level to predict donation behavior (Kottasz, 2004). Traditional direct mail fundraising uses past responses to predict future ones based on donation recency, frequency and amount (Verhaert \& Van den Poel, 2011). Donor motivations are also affected by intrinsic factors that stem from the psychological traits of a person. For instance, researchers examine the effect of self-perceived generosity and religiosity on charitable giving (Noor et al., 2015). Empathic concern and personal distress may lead to a strong desire to help others and perform pro-social tasks (Verhaert \& Van den Poel, 2011). As donating money can be regarded as a sacrifice, what motivates such an altruistic act is often the belief that it will eventually be rewarded in the future (C.-J. Liu \& Hao, 2017).

The growth of the Internet population fuels digital philanthropy that undergoes tremendous transformation over the years (Y.-M. Li, Wu, Hsieh, \& Liou, 2020; Reddick \& Ponomariov, 2012). Instead of using the predictors that pertain to traditional donations, studies on online donation behavior adopt variables concerning fundraising organizations and technical features that the Internet brings into the realm of charitable behavior. For example, researchers integrated Azjen's Theory of Planned Behavior with variables such as project characteristics, trust in the organization, and trust in the Internet to predict a person's attitude toward online donation (Treiblmaier \& Pollach, 2006). 
Emerging from the social media tide, crowdfunding is open to anyone who wishes to raise funds or make a donation. Charitable organizations catch the trend by building crowdfunding sites to host donation-based projects. Such websites have the potential to enhance social development, especially in developing countries (Wash, 2013). Crowdfunding sites offer a new channel for charitable giving, thereby opening up additional dimensions of factors that affect donation behavior. In a recent study, social network site features are included, together with variables related to project, organization, and trust (Sura, Ahn, \& Lee, 2017).

When online charitable donation takes the form of crowdfunding, the process of online donation becomes analogous to the process of online shopping. Users go through the interfaces similar to those on e-commerce websites to complete the steps required for donation. Like making purchases online, a donor chooses a crowdfunding website, search for donation projects, evaluate them (sometimes by interacting with donees), choose one or more projects, and make an online payment. Thus, some key concepts in the studies of online shopping are relevant to crowdfunding. In particular, consumer trust developed by Gefen (2000) is well regarded as an important construct that mediates the relationships between user perceptions and behavioral outcomes. Researchers expand the trust model by adding privacy protection, perceived security, information quality, familiarity, and reputation as predictors of consumer trust (Kim, Ferrin, \& Rao, 2008).

\section{Research Framework}

In traditional psychological theories, the unit of analysis is a human action between a subject and an object. For example, the technology acceptance model (TAM) based on the theory of reasoned action uses the same outcome variable behavioral intention to describe how likely a user (i.e., subject) is to use a system (i.e., object). Such a conceptualization is simple but cannot 
be used to examine crowdfunding behavior as it involves both technology use and social interaction.

In contrast, Activity Theory is not action-based but conceptualizes a human activity as an endeavor in which each subject attempts to transform an object into an expected outcome through the use of certain tools (Engeström, 2001). There can be multiple subjects to work toward one objective, and they form a community under the same behavioral context. How subjects in a community communicate with each other is regulated by rules, and how they work on the same object is regulated by division of labor.

Based on the use of social information systems, crowdfunding can be regarded as a technology-mediated and collaborative human activity, as shown in Figure 1. A crowdfunding platform comprises the projects hosted on its website and the users including both donors and donees. Through the mediation of the website (tool), each user (subject) can set up and/or access a project (object) for donation (outcome). Together, donors and donees form a crowd (community): they interact with each other following online rules and make certain contributions to the project based on their roles and capabilities that define the division of labor.

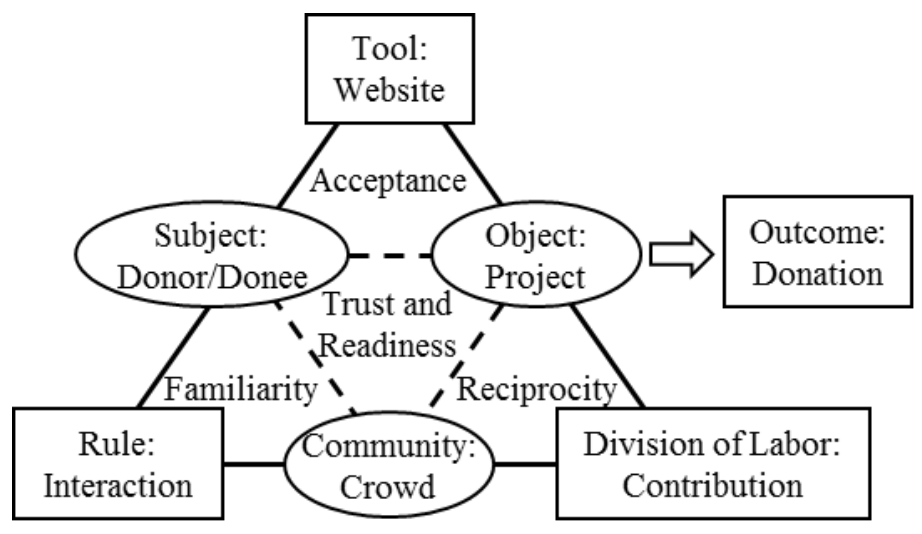

Figure 1. Crowdfunding Activity 
The three actions that a user takes in the crowdfunding activity - navigating the website, interacting with the crowd, and contributing to the project - result in corresponding user experiences in terms of website acceptance, crowd familiarity, and donation reciprocity. These experiences lead to the formation of user trust in the platform and readiness to participate in crowdfunding. The understanding leads to a research model, as shown in Figure 2.

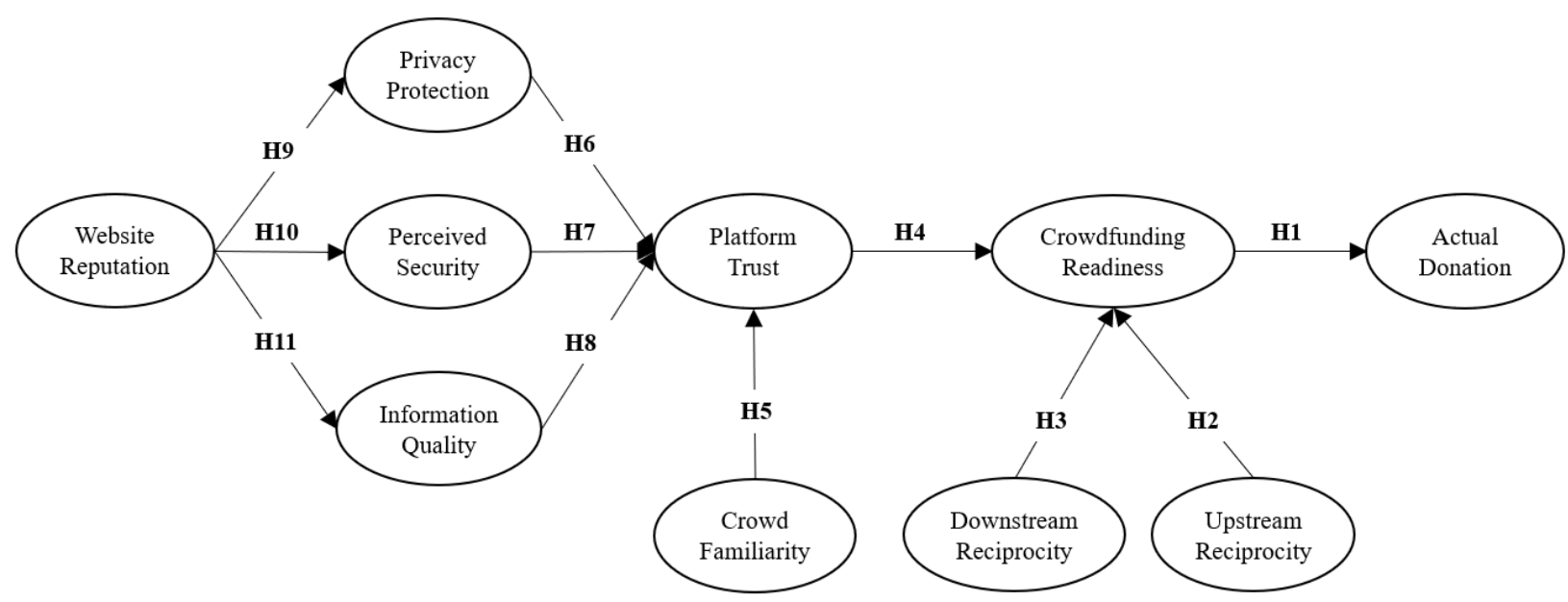

Figure 2. Research Model

Among the main endogenous variables to be predicted, Crowdfunding Readiness mediates the relationship between Platform Trust and Actual Donation. The predicting variables can be categorized into three groups: 1) website acceptance (Website Reputation, Privacy Protection, Perceived Security, and Information Quality); 2) crowd familiarity; and 3) donation reciprocity (Upstream Reciprocity, and Downstream Reciprocity). In terms of the ultimate outcome variable, this study goes beyond the psychological tendency that most studies focus on, especially behavioral intention. Rather it examines Actual Donation in terms of the frequency and amount of donation as well as the number of projects supported within a period of time. Unlike the rest psychological constructs in the model, this one captures overt behavior as the eventual behavioral outcome of crowdsourcing activity. 
Most studies use behavioral intention as the direct antecedent to actual behavior. For instance, Smith and McSweeney (2007) use it to capture how likely a donor is to make monetary donations. However, the intention is action-based as it is a concept originated in the theory of reasoned action (TRA) and later used in the theory of planned behavior (TPB) and many psychological frameworks (Ajzen, 1991). Using the activity as the unit of analysis, this study conceptualizes Crowdfunding Readiness as the psychological tendency for a person to participate in a crowdfunding activity, including website-, interaction- and contribution-related actions. This leads to the first research hypothesis:

H1. Crowdfunding Readiness positively affects Actual Donation.

All other variables are adapted from the literature on e-commerce and donation behavior. Essential to mutual support in social collaboration, reciprocity pertains to the belief that one receives from another is due to what the former has done to the latter (Fehr \& Rockenbach, 2004). Thus, reciprocity is considered as a primary component of donation behavior (Khadjavi, 2016). There are two directions of reciprocity: upstream reciprocity and downstream reciprocity (Nowak $\&$ Sigmund, 2005). In charitable donation, upstream reciprocity concerns the positive impacts on others from giving out social kindness, whereas downstream reciprocity concerns the anticipation of receiving rewards for good deeds in the future (C.-J. Liu \& Hao, 2017). Both are likely to enhance user readiness to participate in crowdfunding activity.

H2. Upstream Reciprocity positively affects Crowdfunding Readiness.

H3. Downstream Reciprocity positively affects Crowdfunding Readiness.

In a social context, trust is important for people to feel comfortable interacting with each other based on the assumption that proper behavior can be expected (Gefen, 2000). Unlike the traditional conceptualization of trust based on long-term human relationship building, e-commerce 
user trust depends on the authenticity of digital content and the transaction process hosted on a site (Grabosky, 2001). In this study, Platform Trust, a user's trust toward a crowdfunding platform as a social information system, concerns the trustworthiness of other donors/donees as well as the authenticity of project content. Researchers showed the direct influence of e-commerce user trust on purchase intention (Gefen, 2000; Kim et al., 2008; Rouibah, Lowry, \& Hwang, 2016; Teo \& Liu, 2007). Similarly, Platform Trust has a positive impact on Crowdfunding Readiness.

H4. Platform Trust positively affects Crowdfunding Readiness.

The trust of e-commerce users in the outcome of future transactions is shaped by their past experiences. Such experiences that help reduce uncertainty in decision-making can be summarized as website familiarity in terms of the knowledge and understanding of a site's purpose, how it works and how to use it (Gefen, 2000; Kim et al., 2008). Based on it, this study conceptualizes Crowd Familiarity as a user's knowledge of the community on a crowdfunding platform and how to interact with its members to have a better understanding of donation projects. As familiarity is considered a predecessor of trust, hence the following hypothesis (Gefen, 2000).

H5. Crowd Familiarity positively affects Platform Trust.

The main threats to user trust to e-commerce websites include information security breach and customer privacy compromise (M.-S. Chen, Han, \& Yu, 1996). Similar to online consumers who disclose personal information, crowdfunding users enter personal and financial information into website databases to complete donation transactions. When crowdfunding sites demonstrate the effort to protect users from security and privacy compromises, user trust increases (Kim et al., 2008). This study defines Privacy Protection and Perceived Security as a user's perceptions of a crowdfunding site's efforts to keep personal information collected confidential and safeguard it with all means. 
H6. Privacy Protection positively affects Platform Trust.

H7. Perceived Security positively affects Platform Trust.

Just like an e-commerce website needs to provide accurate information about products and transactions, a crowdfunding site must give reliable and sufficient information regarding the donation projects and processes so that users can make informed decisions $(\mathrm{Xu}, 2018)$. Quality information supports fundraising efforts by helping legitimize donation projects (Gerber, Hui, \& Kuo, 2012). When users see the efforts made by crowdfunding sites to ensure that information is always complete and up-to-date, their trust is likely to increase (Kim et al., 2008).

H8. Information Quality positively affects Platform Trust.

E-commerce research suggests that whether a website is well regarded makes a difference in user trust (Jarvenpaa, Tractinsky, \& Vitale, 2000; Kim et al., 2008; Teo \& Liu, 2007). Accordingly, Website Reputation concerns a consumer's impression of an Internet store based on public opinions (Jarvenpaa et al., 2000). It is an organizational asset built upon continuous efforts to establish a positive image and good customer relationships (Teo \& Liu, 2007). Researchers used fundraiser reputation to predict traditional donation behavior (Baruch \& Sang, 2012). In the crowdfunding activity, the website is the technical tool whereas the platform comprises users and projects. Rather than using Website Reputation to predict Platform Trust directly, this study uses it as the antecedent of website-related perceptions. The feedback (e.g., reviews and word-ofmouth) from experienced users establishes the reputation of a website that shapes the perceptions of newcomers (Kim et al., 2008).

H9. Website Reputation positively affects Privacy Protection.

H10. Website Reputation positively affects Perceived Security.

H11. Website Reputation positively affects Information Quality. 


\section{Methodology}

To test the research model, survey observations were collected with online questionnaires. The Appendix lists measurement items, most of which adapted from existing studies. Unlike the other constructs in the research model, Actual Donation is a formative latent variable. Compared with covariance-based structural equation modeling (SEM), SEM based on partial least squares (PLS) is capable of handling formative latent variables in addition to reflective ones. This study conducts measurement validation first and then model testing with SmartPLS 3. For an empirical study using SEM, a larger sample size is conducive to higher estimation accuracy but it should be under 1,000 to avoid the statistical overpower in significance tests (Joseph F. Hair, Black, Babin, \& Anderson, 2011, p. 174).

Data were collected from multiple countries of different cultures and at development stages, including China, the Philippines and the USA. Links to online questionnaires were posted on various social media platforms such as Facebook and WeChat in order to reach respondents. For the questionnaires used in China, the measurement items were translated into the Chinese language by the authors. Then, they were translated back to English by a certified translation service. Several native English speakers reviewed the back-translated questionnaires and all indicated no difficulty in understanding the questions. Then they read the original English questionnaire, and no significant deviations were detected.

A total of 744 valid responses were collected: 252 from China (33.9\%), 215 from the Philippines (28.9\%), and 277 from the USA (37.2\%). There were 59.7\% female and $40.3 \%$ male participants. Around two thirds were under age 30 (59.0\%) and the majority had higher education (78.9\%). The distribution of monthly incomes was largely normal with more than half within one 
standard deviation from the medium (55.5\%). Most had two or more years of Internet experience (92.6\%) and religiosity was largely balanced (47.4\% Yes versus $52.6 \%$ No).

Table 1. Sample Profiles $(\mathrm{N}=744)$

\begin{tabular}{|c|c|c|}
\hline Characteristics & Number & $\%$ \\
\hline \multicolumn{3}{|l|}{ Country } \\
\hline Philippines & 215 & 28.9 \\
\hline China & 252 & 33.9 \\
\hline United States & 277 & 37.2 \\
\hline \multicolumn{3}{|l|}{ Gender } \\
\hline Female & 444 & 59.7 \\
\hline Male & 300 & 40.3 \\
\hline \multicolumn{3}{|l|}{ Age } \\
\hline 21 or below & 151 & 20.3 \\
\hline $21-30$ & 288 & 38.7 \\
\hline $31-40$ & 171 & 23.0 \\
\hline $41-50$ & 67 & 9.0 \\
\hline $51-60$ & 31 & 4.2 \\
\hline 61 or above & 36 & 4.8 \\
\hline \multicolumn{3}{|l|}{ Education } \\
\hline No high school & 5 & .7 \\
\hline High school diploma & 20 & 2.7 \\
\hline Associate degree & 132 & 17.7 \\
\hline Bachelor degree & 416 & 55.9 \\
\hline Master's degree & 154 & 20.7 \\
\hline Doctoral degree & 17 & 2.3 \\
\hline \multicolumn{3}{|c|}{ Net Income (monthly in USD) } \\
\hline$<500$ & 151 & 20.3 \\
\hline 500-999 & 67 & 9.0 \\
\hline $1,000-1,499$ & 112 & 15.1 \\
\hline $1,500-1,999$ & 191 & 25.7 \\
\hline $2,000-2499$ & 109 & 14.7 \\
\hline $2,500-2,999$ & 53 & 7.1 \\
\hline$>3,000$ & 61 & 8.2 \\
\hline \multicolumn{3}{|l|}{ Internet Experience } \\
\hline Less than 1 year & 23 & 3.1 \\
\hline $1-2$ years & 32 & 4.3 \\
\hline $2-3$ years & 96 & 12.9 \\
\hline 3-4 years & 75 & 10.1 \\
\hline More than 4 years & 518 & 69.6 \\
\hline \multicolumn{3}{|l|}{ Religious } \\
\hline No & 391 & 52.6 \\
\hline Yes & 353 & 47.4 \\
\hline
\end{tabular}


As the data were collected with survey questionnaires, this study assessed the common method bias (CMB) using Harman's test based on principal component analysis (Podsakoff, MacKenzie, \& Podsakoff, 2012). No dominant component explaining more than 50\% of total variance emerged, which dismissed strong CMB. In addition to the traditional approach, this study used the second-smallest positive correlation among the manifest variables as a conservative estimate of CMB. As this method is not based on particular measurement theories, it has been used recently by researchers (Durcikova, Lee, \& Brown, 2018; Leonidou, Christodoulides, Kyrgidou, \& Palihawadana, 2017; Yang, Sun, Zhang, \& Wang, 2019). In this study, the second-smallest positive correlation was 0.005 , which was used to adjust the correlations among all manifest variables in the research model. All significant correlations remained so after the proxy CMB influence was removed, further dismissing the threat of CMB. Non-response bias was also assessed. The MANOVA test comparing early and late responses showed no significant difference (Wilks' lambda $=0.993, p=0.790$ ). The insensitivity of responses to response time indicated little nonresponse bias (Armstrong \& Overton, 1977).

\section{Results}

In this study, Actual Donation is a formative latent variable, and the measurement validation is different from that for other reflective latent variables. In particular, the three indicators of Actual Donation - number of projects supported, frequency of donations, and donated amount - are different dimensions that are not supposed to covary. As shown in Table 2, the measurement validation based on the variation inflation factor (VIF) confirms such distinctiveness: the largest VIF value was 1.26 (number of projects), well below the threshold of 5 (Joe F. Hair, Hult, Ringle, \& Sarstedt, 2016). In addition, all the outer loadings and outer weights of formative 
indicators were highly significant, supporting their absolute and relative importance to Actual Donation (Joe F. Hair et al., 2016).

Table 2. Validating the Formative Construct of Actual Donation

\begin{tabular}{cclccc}
\hline Construct & Indicator & \multicolumn{1}{c}{ Description } & Loading & Weight & VIF \\
\hline Actual Donation & AD1 & Number of projects supported & $0.67^{* * * *}$ & $0.56^{* * * *}$ & 1.26 \\
& AD2 & Frequency of donations & $0.51^{* * *}$ & $0.56^{* * * *}$ & 1.04 \\
& AD3 & Donated amount & $0.73^{* * *}$ & $0.46^{* * *}$ & 1.24 \\
\hline
\end{tabular}

Note: $* * * p<0.001$; two-tailed test.

Table 3 reports the results of descriptive and reliability analyses for reflective constructs.

The average responses exhibit expected patterns: most of them are above the midpoint of 4 for the 7-level Likert scale used by all the questionnaire items. The only exception is Privacy Protection: its items are reverse coded, leading to relatively negative responses. Coefficient alpha $(\alpha)$ and composite reliability (CR) values were all above 0.7 , indicating an acceptable level of reliability for each construct. Similarly, the Average Variance Extracted (AVE) values were well above 0.5, supporting convergent validity.

Table 3. Descriptive and Reliability Analyses for Reflective Constructs

\begin{tabular}{lccccc}
\hline \multicolumn{1}{c}{ Construct } & Mean & SD & $\alpha$ & CR & AVE \\
\hline Website Reputation (WR) & 4.76 & 1.30 & 0.91 & 0.95 & 0.85 \\
Privacy Protection (PP) & 3.13 & 1.40 & 0.95 & 0.97 & 0.88 \\
Perceived Security (PS) & 4.62 & 0.99 & 0.78 & 0.87 & 0.70 \\
Information Quality (IQ) & 4.81 & 1.11 & 0.94 & 0.96 & 0.84 \\
Crowd Familiarity (CF) & 4.31 & 1.43 & 0.92 & 0.94 & 0.81 \\
Platform Trust (PT) & 4.62 & 1.03 & 0.91 & 0.94 & 0.79 \\
Upstream Reciprocity (UR) & 4.92 & 1.12 & 0.95 & 0.96 & 0.86 \\
Downstream Reciprocity (DR) & 4.89 & 1.21 & 0.81 & 0.89 & 0.73 \\
Crowdfunding Readiness (CR) & 4.50 & 1.21 & 0.91 & 0.93 & 0.78 \\
\hline
\end{tabular}

As for discriminant validity, Table 4 shows that the smallest square root of AVE (i.e., 0.83) was higher than the largest factor correlation (i.e., 0.80). As the shared variance among the indicators of each construct exceeds that across constructs, discriminant validity was supported. 
Not all the correlations among psychological constructs were very strong, especially those associated with Privacy Protection. Together with this, the use of objective measures for Actual Donation as a formative outcome variable mitigates the potential impacts of any common method bias in model estimation.

Table 4. Factor correlations

\begin{tabular}{lccccccccc}
\hline \multicolumn{1}{c}{ Construct } & WR & PP & PS & IQ & CF & PT & UR & DR & CR \\
\hline Website Reputation (WR) & .92 & & & & & & & & \\
Privacy Protection (PP) & $.19^{* *}$ & .94 & & & & & & & \\
Perceived Security (PS) & $.47^{* *}$ & $.15^{* *}$ & $\mathbf{. 8 3}$ & & & & & & \\
Information Quality (IQ) & $.76^{* *}$ & $.18^{* *}$ & $.56^{* *}$ & .92 & & & & & \\
Crowd Familiarity (CF) & $.61^{* *}$ & $.16^{* *}$ & $.39^{* *}$ & $.58^{* *}$ & .90 & & & & \\
Platform Trust (PT) & $.66^{* *}$ & $.20^{* *}$ & $.63^{* *}$ & $.80^{* *}$ & $.51^{* *}$ & $\mathbf{. 8 9}$ & & & \\
Upstream Reciprocity (UR) & $.56^{* *}$ & $.12^{* *}$ & $.55^{* *}$ & $.64^{* *}$ & $.47^{* *}$ & $.64^{* *}$ &. $\mathbf{9 3}$ & & \\
Downstream Reciprocity (DR) & $.27^{* *}$ & .00 & $.27^{* *}$ & $.35^{* *}$ & $.30^{* *}$ & $.34^{* *}$ & $.39^{* *}$ & $\mathbf{. 8 5}$ & \\
Crowdfunding Readiness (CR) & $.43^{* *}$ & $.09^{*}$ & $.52^{* *}$ & $.56^{* *}$ & $.48^{* *}$ & $.58^{* *}$ & $.68^{* *}$ & $.41^{* *}$ & $\mathbf{. 8 8}$ \\
\hline
\end{tabular}

Note: $* * p<0.01$; $*<<0.05$; two-tailed test. The bolded values on the diagonal are the square roots of the average variance extracted (AVE).

After measurement validation, the structural model was estimated. Figure 3 shows the path coefficients of hypothesized relationships and $R$-squared values for endogenous variables. The significance test was based on bootstrapping, which is a nonparametric procedure based on a large number of subsamples randomly drawn from the data with replacement (Joe F. Hair et al., 2016). To increase the precision and consistency of PLS estimation, this study used 10,000 subsamples for bootstrapping. Out of the eleven research hypotheses presented, ten were significant and one was marginally significant $(p$-value $=0.0568)$, which was the relationship between Crowd Familiarity and Platform Trust. This suggests that user trust is less influenced by how well they know each other. The main psychological outcomes of crowdfunding activity, Platform Trust and Crowdfunding Readiness, had more than half of the variance explained by their antecedents. Thus, the main aspects of influence were captured by variables related to website acceptance, crowd familiarity, and donation reciprocity. At the same time, Crowdfunding Readiness was a significant 
predictor of Actual Donation. The $R$-squared value was smaller, which is expected as there are many other factors (e.g., income) that influence overt donation behavior.

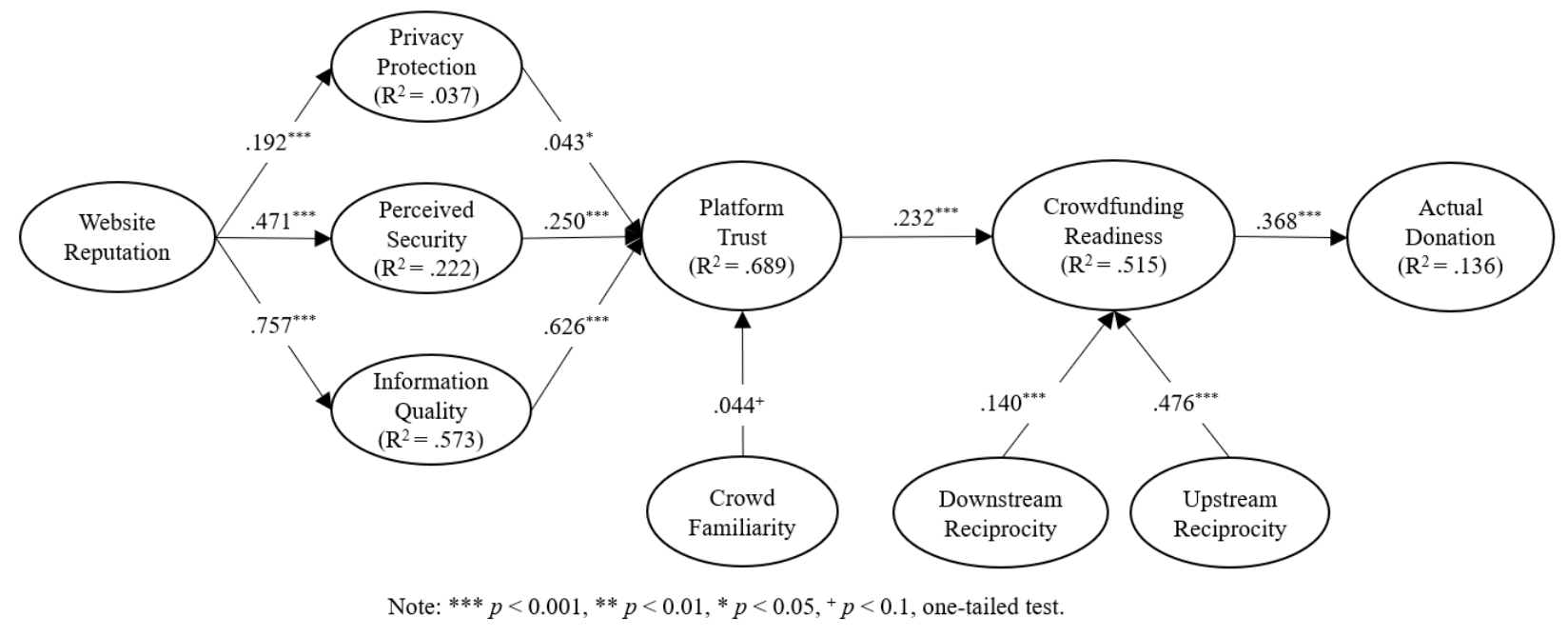

Figure 3. Model Estimates

To check the robustness of results, this study obtains model estimates with each country sample. As shown in Table 5, eight out of the 11 relationships remained significant across three samples. The relationship between Crowd Familiarity and Platform Trust (H5) was significant at the 0.05 level for the China sample, marginally significant at the 0.1 level for the USA sample, and insignificant for the Philippines sample. The relationship between Privacy Protection and Platform Trust (H6) was significant at the 0.05 level for the China sample, but insignificant for the USA and Philippines samples. The relationship between Website Reputation and Privacy Protection (H9) was marginally significant at the 0.1 level for the China sample, but insignificant for the USA and Philippines samples. It is possible that national cultures and developmental stages made some differences in the hypothesized relationships. Nevertheless, the effects were largely consistent, supporting the overall validity of the research model. 
Table 5. Estimates by Country Samples

\begin{tabular}{llll}
\hline \multicolumn{1}{c}{ Relationship } & China & Philippines & U.S. \\
\hline H1: Crowdfunding Readiness -> Actual Donation & $.265^{* * *}$ & $.452^{* * *}$ & $.259^{* * *}$ \\
H2: Upstream Reciprocity -> Crowdfunding Readiness & $.674^{* * *}$ & $.477^{* * *}$ & $.299^{* * *}$ \\
H3: Downstream Reciprocity -> Crowdfunding Readiness & $.125^{* * *}$ & $.099^{*}$ & $.190^{* * *}$ \\
H4: Platform Trust -> Crowdfunding Readiness & $.186^{* * *}$ & $.327^{* * *}$ & $.258^{* * *}$ \\
H5: Crowd Familiarity -> Platform Trust & $.118^{*}$ & -.004 & $.064^{+}$ \\
H6: Privacy Protection -> Platform Trust & $.069^{*}$ & .019 & $.037^{*}$ \\
H7: Perceived Security -> Platform Trust & $.308^{* * *}$ & $.257^{* * *}$ & $.171^{* * *}$ \\
H8: Information Quality -> Platform Trust & $.531^{* * *}$ & $.564^{* * *}$ & $.708^{* * *}$ \\
H9: Website Reputation -> Privacy Protection & $.114^{+}$ & .049 & .051 \\
H10: Website Reputation -> Perceived Security & $.411^{* * *}$ & $.486^{* * *}$ & $.583^{* * *}$ \\
H11: Website Reputation -> Information Quality & $.751^{* * *}$ & $.679^{* * *}$ & $.775^{* * *}$ \\
\hline
\end{tabular}

Note: $* * * p<0.001,{ }^{* *} p<0.01,{ }^{*} p<0.05,{ }^{+} p<0.1$, one-tailed test.

6. Theoretical and Practical Implications

The results generally support the conceptualization of crowdfunding activity. Compared with the action-based frameworks, such as the Theory of Planned Behavior and Technology Acceptance Model, Activity Theory allows for the inclusion of technological artifact, user community, and project task in one unit of analysis. This is essential for the study of crowdfunding behavior based on the use of social information systems. The three types of actions in crowdfunding activity in terms of website acceptance, crowd familiarity, and donation reciprocity lead to the identification of predictor variables. Accordingly, these variables are tool-, communityand task-oriented. Together, they explain user behavior on crowdfunding platforms, which is not just about technology use, but collaborative in nature.

For the purpose of separating the technological and social aspects of crowdfunding user behavior, this study distinguishes a website as the technical tool and a platform as the aggregate of the user community and project object. Through the mediation of the website, users collaborate with each other on projects. In this sense, the setup of a crowdfunding website does not constitute 
the establishment of a social information system, until users and projects form the platform. During the process, users will develop their own communication rules and division of labor, over which website developers and owners may not have much control.

Correspondingly, there are two psychological outcome variables, Platform Trust and Crowdfunding Readiness. The former captures the user's general perception of the social information system, and the latter indicates the behavioral inclination to participate in the toolmediated collaborative activity. In the conceptualization of crowdfunding activity, each individual uses the website to access project information and interact with others. Thus, website acceptance variables and Crowd Familiarity predict Platform Trust. Meanwhile, it is hard for a person to manipulate the division of labor, which is collectively formed by a crowd community. In this way, donation reciprocity variables explain Crowdfunding Readiness, together with Platform Trust.

This study adopts one overt outcome variable, Actual Donation, to captures the bottomline consequence of crowdfunding activity. This goes beyond Behavioral Intention commonly used as the psychological outcome in the existing behavioral studies of donation-based crowdfunding (L. Liu, 2018; T. Wang et al., 2019). Behavioral Intention may predict how likely a user is to make a donation, but there are other aspects of observable behavior regarding user participation on crowdfunding platforms, such as website navigation and interaction engagement (Bekkers \& Wiepking, 2011). The formative construct of Actual Donation comprises three dimensions in terms of the number of projects supported as well as the frequency and amount of donations. These dimensions embody important aspects of observable user behavior on a donationbased crowdfunding platform. For instance, the number of projects supported captures a user's navigation of the website and interaction with others on the platform. 
In addition to theoretical implications, specific findings yield helpful practical implications. First of all, the most significant predictor of Platform Trust is Information Quality. Individuals or organizations coordinating fundraising projects must pay close attention to the content they put on the website. They need to make sure that the project details donors care about be highlighted in the description, and the information provided be accurate and complete. Fundraisers may put in more efforts to showcase their projects with pictures and videos, as well as testimonies from credible individuals or organizations. Also, fundraisers must make sure that they update the information in a regular and timely manner.

To make a successful crowdfunding platform, it is important for donors and donees to work closely together to cultivate a sense of family. This would boost up Crowd Familiarity and Donation Reciprocity that further enhance Platform Trust and Crowdfunding Readiness. In particular, Upstream Reciprocity is found to have a large impact on Crowdfunding Readiness. Donees need to communicate fundraising progress in a clear and proactive way. Potential donors will be encouraged and convinced if they see that individual donations, small or large, matter to the whole project. After the fundraising period ends, the donee should provide sufficient feedback to donors on the intermediate and final outcome of the funded project.

It is the responsibility of the crowdfunding site to facilitate the information exchange between donees and donors in a timely manner. For instance, a website may provide a support system that reminds donees to update donors on project progress. Many individual donees do not have much experience, and crowdfunding sites play a big role in guiding them through the funding process. To crowdfunding platform users, privacy is less a concern than security, probably due to its social information system nature. Nevertheless, they want their personal information protected 
by all means. Website Reputation is closely related to Perceived Security and Information Quality, suggesting that site developers and managers devote efforts to both.

\section{Conclusion}

This study examines the critical success factors of crowdfunding platforms as social information systems. Based on Activity Theory, it conceptualizes crowdfunding activity, and develops a research model. The empirical results based on survey observations confirm most of the hypothesized relationships, thereby supporting the validity of activity conceptualization. The overall findings regarding the hypothesized relationships provide insights on the best practices of donation-based crowdfunding.

Certain limitations must be considered before making inferences about specific findings. Although observations were collected from multiple countries, they are far from representative of the whole population. Therefore, the extrapolation of detailed results should be made with caution. Compared with millions of users on popular crowdfunding platforms, the sample size of this study is far too small. It is preferable to combine behavioral research using survey observations with platform-specific research using big data to answer both the "why" and "how" questions regarding user participation in crowdfunding. In this way, the hypothesized relationships evaluated based on sampling can be further validated with in-the-field analyses on larger portions of the population.

In this study, some of the model estimates varied across the China, Philippines and USA samples, perhaps dues to cultural and developmental differences. It is expected that observations collected from more countries of distinct cultures and economies will help reveal the potential moderating mechanisms involved. Future studies may collect observations from other continents, such as Europe and Africa, to enhance the generalizability of findings. 


\section{References}

Ajzen, I. (1991). The theory of planned behavior. Organizational Behavior and Human Decision Processes, 50(2), 179-211.

Armstrong, J. S., \& Overton, T. S. (1977). Estimating nonresponse bias in mail surveys. Journal of marketing research, 14(3), 396-402.

Baruch, Y., \& Sang, K. J. C. (2012). Predicting MBA graduates' donation behavior to their alma mater. Journal of Management Development, 3(8), 808-825.

Bekkers, R., \& Wiepking, P. (2011). A Literature Review of Empirical Studies of Philanthropy: Eight Mechanisms That Drive Charitable Giving. Nonprofit and Voluntary Sector Quarterly, 40(5), 924-973. doi:10.1177/0899764010380927

Bi, S., Liu, Z., \& Usman, K. (2017). The influence of online information on investing decisions of reward-based crowdfunding. Journal of Business Research, 71, 10-18.

Bock, G.-W., Zmud, R. W., Kim, Y.-G., \& Lee, J.-N. (2005). Behavioral Intention Formation in Knowledge Sharing: Examining the Roles of Extrinsic Motivators, Social-Psychological Forces, and Organizational Climate. MIS Quarterly, 29(1), 87-111.

Chen, M.-S., Han, J., \& Yu, P. S. (1996). Data Mining: An Overview from a Database Perspective. IEEE Transactions on Knowledge and Data Engineering, 8(6), 866-883.

Chen, S., Thomas, S., \& Kohli, C. (2016). What Really Makes a Promotional Campaign Succeed on a Crowdfunding Platform?: Guilt, Utilitarian Products, Emotional Messaging, And Fewer But Meaningful Rewards Drive Donations. Journal of Advertising Research, 56(1), 81-94.

Cho, M., \& Kim, G. (2017). A cross-cultural comparative analysis of crowdfunding projects in the United States and South Korea. Computers in Human Behavior, 72, 312-320. doi:https://doi.org/10.1016/j.chb.2017.03.013

Cox, J., Nguyen, T., Thorpe, A., Ishizaka, A., Chakhar, S., \& Meech, L. (2018). Being seen to care: the relationship between self-presentation and contributions to online pro-social crowdfunding campaigns. Computers in Human Behavior, 83, 45-55.

Durcikova, A., Lee, A. S., \& Brown, S. A. (2018). Making rigorous research relevant: Innovating statistical action research. MIS Quarterly, 42(1), 241-263.

Dushnitsky, G., Guerini, M., Piva, E., \& Rossi-Lamastra, C. (2016). Crowdfunding in Europe: Determinants of platform creation across countries. California management review, 58(2), 44-71.

Engeström, Y. (2001). Expansive learning at work: Toward an activity theoretical reconceptualization. Journal of education and work, 14(1), 133-156.

Fehr, E., \& Rockenbach, B. (2004). Human altruism: Economic, neural, and evolutionary perspectives. Current Opinion in Neurobiology, 14(6), 784-790.

Gefen, D. (2000). E-commerce: the role of familiarity and trust. The International Journal of Management Science, 28(5), 725-737.

Gerber, E. M., Hui, J. S., \& Kuo, P. Y. (2012). Crowdfunding: why people are motivated to post and fund projects on crowdfunding platforms. Paper presented at the International Workshop on Design, Influence, and Social Technologies: Techniques, Impacts and Ethics.

Ghani, N. A., Hamid, S., Hashem, I. A. T., \& Ahmed, E. (2019). Social media big data analytics: A survey. Computers in Human Behavior, 101, 417-428.

Grabosky, P. (2001). The nature of trust online. The Age, 23(1), 1-12. 
Hair, J. F., Black, W. C., Babin, B. J., \& Anderson, R. E. (2011). Multivariate Data Analysis (7 ed.). Beijing: China Machine Press.

Hair, J. F., Hult, T., Ringle, C., \& Sarstedt, M. (2016). A Primer on Partial Least Squares Structural Equation Modeling (PLS-SEM) (2 ed.). Thousand Oaks, CA: Sage.

Herrero, Á., Hernández-Ortega, B., \& San Martín, H. (2020). Potential funders' motivations in reward-based crowdfunding. The influence of project attachment and business viability. $\begin{array}{lllll}\text { Computers in Human } 106240 . & \end{array}$ doi:https://doi.org/10.1016/j.chb.2019.106240

Hoefer, R. (2012). From website visitor to online contributor: three Internet fundraising techniques for nonprofits. National Associations of Social Workers, 57(4), 361-365.

Jarvenpaa, S. L., Tractinsky, N., \& Vitale, M. (2000). Consumer trust in an Internet store. Information Technology and Management, 1(1-2), 45-71.

Khadjavi, M. (2016). Indirect reciprocity and charitable giving: Evidence from a field experiment. Management Science, 63(11), 3531-3997.

Kim, D. J., Ferrin, D. L., \& Rao, H. R. (2008). A trust-based consumer decision-making model in electronic commerce: e role of trust, perceived risk, and their antecedents. Decision Support Systems, 44(2), 544-564.

Kottasz, R. (2004). Differences in the Donor Behavior Characteristic of Young Affluent Males and Females: Empirical Evidence From Britain. International Journal of Voluntary and Non-profit Organisations, 15(2), 181-203.

Lee, D., \& Park, J. (2020). The relationship between a charity crowdfunding project's contents and donors' participation: An empirical study with deep learning methodologies. Computers in Human Behavior, 106, 106261. doi:https://doi.org/10.1016/j.chb.2020.106261

Lee, I. (2018). Social media analytics for enterprises: Typology, methods, and processes. Business Horizons, 61(2), 199-210. doi:https://doi.org/10.1016/j.bushor.2017.11.002

Leonidou, L. C., Christodoulides, P., Kyrgidou, L. P., \& Palihawadana, D. (2017). Internal drivers and performance consequences of small firm green business strategy: The moderating role of external forces. Journal of business ethics, 140(3), 585-606.

Li, Y.-M., Wu, J.-D., Hsieh, C.-Y., \& Liou, J.-H. (2020). A social fundraising mechanism for $\begin{array}{lllll}\text { charity crowdfunding. Decision Support Systems, } 129, & 13170 .\end{array}$ doi:https://doi.org/10.1016/j.dss.2019.113170

Li, Y.-Z., He, T.-L., Song, Y.-R., Yang, Z., \& Zhou, R.-T. (2018). Factors impacting donors' intention to donate to charitable crowd-funding projects in China: a UTAUT-based model. Information, Communication \& Society, 21(3), 404-415. doi:10.1080/1369118X.2017.1282530

Liu, C.-J., \& Hao, F. (2017). Reciprocity belief and gratitude as moderators of the association between social status and charitable giving. Personality and Individual Differences, 111, 46-50.

Liu, L. (2018). Empathy or perceived credibility? An empirical study on individual donation behavior in charitable crowdfunding. Internet Research, 28(3), 623-651. doi:10.1108/IntR06-2017-0240

Massolution (Producer). (2015). CF - The Crowdfunding Industry Report. Retrieved from http://www.crowdsourcing.org/editorial/global- crowdfunding-market-to-reach- 344b-in2015-predicts-massolutions-2015cf-industry-report/45376

McLure Wasko, M., \& Faraj, S. (2005). Why should I share? Examining social capital and knowledge contribution in electronic networks of practice. MIS Quarterly, 29(1), 35-37. 
Neubaum, G., Rösner, L., Rosenthal-von der Pütten, A. M., \& Krämer, N. C. (2014). Psychosocial functions of social media usage in a disaster situation: A multi-methodological approach. Computers in Human Behavior, 34, 28-38. doi:https://doi.org/10.1016/j.chb.2014.01.021

Noor, A., Isa, N., Irpan, H., Bahrom, H., Salleh, A., \& Ridzuan, A. (2015). Characteristic Affecting Charitable Donations Behavior: Empirical Evidence from Malaysia. Procedia Economics and Finance, 31, 563-572.

Nowak, M. A., \& Sigmund, K. (2005). Evolution of indirect reciprocity. Nature, 437, 1291-1298.

Podsakoff, P. M., MacKenzie, S. B., \& Podsakoff, N. P. (2012). Sources of Method Bias in Social Science Research and Recommendations on How to Control It. Annual Review of Psychology, 63(1), 539-569. doi:10.1146/annurev-psych-120710-100452

Reddick, C. G., \& Ponomariov, B. (2012). The effects of individuals' organization affiliation on their internet donations. Nonprofit and Voluntary Sector Quarterly, 42(6), 1197-1223.

Rouibah, K., Lowry, P. B., \& Hwang, Y. (2016). The effects of perceived enjoyment and perceived risks on trust formation and intentions to use online payment systems: New perspectives from an Arab country. Electronic Commerce Research and Applications, 19, 33-43.

Sahaym, A., Datta, A., \& Brooks, S. (2019). Crowdfunding success through social media: Going beyond entrepreneurial orientation in the context of small and medium-sized enterprises. Journal of Business Research. doi:https://doi.org/10.1016/j.jbusres.2019.09.026

Shneor, R., \& Munim, Z. H. (2019). Reward crowdfunding contribution as planned behaviour: An extended framework. Journal of Business Research, 103, 56-70.

Silver, E., \& Khatri, A. (2016). Endowed by the Crowd? Insights Into the New Wave of Crowdfunding and Its Viability. Journal of Taxation \& Regulation of Financial Institutions, 29(3), 33-44.

Smith, J. R., \& McSweeney, A. (2007). Charitable giving: The effectiveness of a revised theory of planned behaviour model in predicting donating intentions and behaviour. Journal of Community \& Applied Social Psychology, 17(5), 363-386.

Stasik, A., \& Wilczyńska, E. (2018). How do we study crowdfunding? An overview of methods and introduction to new research agenda. Journal of Management and Business Administration. Central Europe, 26(1), 49-78.

Strohmaier, D., Zeng, J., \& Hafeez, M. (2019). Trust, distrust, and crowdfunding: A study on perceptions of institutional mechanisms. Telematics and Informatics, 43, 101252. doi:https://doi.org/10.1016/j.tele.2019.101252

Sura, S., Ahn, J., \& Lee, O. (2017). Factors influencing intention to donate via social network site (SNS): From Asian's perspective. Telematics and Informatics, 34(1), 164-176. doi:https://doi.org/10.1016/j.tele.2016.04.007

Teo, T. S. H., \& Liu, J. (2007). Consumer trust in e-commerce in the United States, Singapore, and China. Omega, 35(1), 22-38.

Treiblmaier, H., \& Pollach, I. (2006). A Framework for Measuring People's Intention to Donate Online. Paper presented at the PACIS 2006 PROCEEDINGS.

Verhaert, G. A., \& Van den Poel, D. (2011). Empathy as added value in predicting donation behavior. Journal of Business Research, 64(12), 1288-1295.

Vulkan, N., Åstebro, T., \& Sierra, M. F. (2016). Equity crowdfunding: A new phenomena. Journal of Business Venturing Insights, 5, 37-49. doi:https://doi.org/10.1016/j.jbvi.2016.02.001

Wang, T., Li, Y., Kang, M., \& Zheng, H. (2019). Exploring individuals' behavioral intentions toward donation crowdfunding: evidence from China. Industrial Management \& Data Systems, 119(7), 1515-1534. doi:10.1108/IMDS-10-2018-0451 
Wang, Z., \& Yang, X. (2019). Understanding backers' funding intention in reward crowdfunding: An elaboration likelihood perspective. Technology in Society, 58, 101149.

Wash, R. (2013). The Value of Completing Crowdfunding Projects. Paper presented at the Seventh International AAAI Conference on Weblogs and Social Media.

$\mathrm{Xu}, \mathrm{L}$. Z. (2018). Will a digital camera cure your sick puppy? Modality and category effects in donation-based crowdfunding. Telematics and Informatics, 35(7), 1914-1924. doi:https://doi.org/10.1016/j.tele.2018.06.004

Yang, Z., Sun, J., Zhang, Y., \& Wang, Y. (2019). Perceived fit between green IS and green SCM: Does it matter? Information \& Management, $56(7), \quad 103154$. doi:https://doi.org/10.1016/j.im.2019.02.009

Zolkepli, I. A., \& Kamarulzaman, Y. (2015). Social media adoption: The role of media needs and innovation characteristics. Computers in Human Behavior, 43, 189-209. doi:https://doi.org/10.1016/j.chb.2014.10.050 
Appendix: Questionnaire items

Construct: Source

Website Reputation: (Kim et al., 2008)

Privacy Protection ${ }^{\mathrm{R}}$ : (Kim et al., 2008)
Measurement Items

The website has a good reputation.

The website is well regarded.

The website is recognized by the public.

I am concerned that the website will use my personal information for other purposes without my authorization. I am concerned that the website will share my personal information with other entities without my authorization. I am concerned about the privacy of my personal information during a donation.

I am concerned that the website will sell my personal information to others without my permission.

Perceived Security: (Kim et al., The website implements security measures to protect donors. 2008)

Information Quality: (Kim et al., 2008)

Crowd Familiarity: (Gefen, 2000)

Platform Trust: (Jarvenpaa et al., 2000)

Upstream Reciprocity: (Bock, Zmud, Kim, \& Lee, 2005)
I feel secure about the electronic payment system of the website.

I am willing to use my credit card on the website to make a donation.

Overall, I think the website provide useful information.

The website provides reliable information.

The website gives sufficient information when I try to make a donation.

I am satisfied with the information that the website provides.

Overall, I am familiar with social interactions on the platform.

I know how to communicate with other users.

I am quick to find out what other donors think about a project.

It is easy to reach out to donees for further information.

The crowdfunding platform is trustworthy.

The crowdfunding platform is reliable.

The crowdfunding platform keeps promises.

The crowdfunding platform has my best interests in mind.

My donations would create new opportunities for the project. My donations would improve how tasks are carried out in the project.

My donations would increase the productivity of the project. My donations would help the project achieve its performance objectives. 
Downstream Reciprocity: (McLure Wasko \& Faraj, 2005)

Crowdfunding Readiness: (Sura et al., 2017)

Actual Donation: new
I know that other people will help me, so it's only fair to help other people.

I trust that someone would help me if I were in a similar situation.

When I help someone, I believe that others will help me when I am in need.

I plan to visit the crowdfunding site in the new future. I am likely to interact with other users on the platform. I am willing to make donations to good projects on the platform.

I would like to engage in crowdfunding when possible.

How many projects have you supported within the last 3 months?

How often do you make donations on the platform within the last 3 months?

How much money have you donated within the last 3 months?

Note: ${ }^{\mathrm{R}}$ - Reversed coding; Survey instruction - Please answer the question based on your recent experiences with a crowdfunding platform that comprises donation projects as well as donors and donees on its website. 